\title{
Left ventricular diastolic function after anthracycline chemotherapy in childhood: relation with systolic function, symptoms, and pathophysiology
}

\author{
Frances A Bu'Lock, Martin G Mott, Anthony Oakhill, Robin P Martin
}

\begin{abstract}
Objectives-To examine left ventricular (LV) diastolic function in patients previously treated with anthracycline drugs for childhood malignancy. To consider clinical relevance, relations with systolic dysfunction, and the pathophysiology of anthracycline cardiotoxicity.

Design-Cross sectional echocardiographic study of LV function.

Setting-Supraregional centre for paediatric cardiology, principal centre for the treatment of childhood malignancy in southwest England.
\end{abstract}

Patients-226 of 236 patients surviving between 6.5 months and 17 (median 5.3) years from initial anthracycline treatment for childhood malignancy attended for clinical and echocardiographic examination. Cumulative anthracycline doses were between 50 and 750 (median 300) $\mathrm{mg} / \mathrm{m}^{2} .22$ patients had also received cardiac irradiation.

Methods-Detailed assessment of transmitral diastolic pulsed wave Doppler flow patterns along with $\mathrm{LV}$ dimensions and systolic function measured by $M$ mode echocardiography.

Main outcome measures-Peak early (E) and atrial (A) phase filling velocities and EA ratio, time and acceleration and deceleration to and from peak $E$ velocity, velocity integrals and ratio, isovolumic relaxation time (IVRT), and heart rate were measured. Results were examined in relation to $\mathrm{LV}$ cavity and posterior wall dimensions and shortening fraction (SF), and compared with paired control data matched for body surface area.

Departments of Paediatric Cardiology and Paediatric Oncology, Bristol

Royal Hospital for Sick Children, St Michael's Hill, Bristol BS2 8BJ

F A Bu'Lock

M G Mott

A Oakhill

R P Martin

Correspondence to:

Dr F A Bu'Lock,

Department of Paediatric

Cardiology, Alder Hey

Children's Hospital, Eaton

Road, Liverpool L12 2AP.

Accepted for publication

11 October 1994 tively normal or enhanced at low anthracycline doses or when SF was preserved, with a shorter IVRT and increased atrial phase filling. Early filling was reduced at higher doses or with reduced SF, with longer IVRT and a further increase in atrial phase filling. A more "restrictive" pattern of diastolic filling (with high $E$ and low $A$ velocities) was seen in some patients, particularly after cardiac irradiation.

Conclusions-Significant abnormalities of diastolic function are associated with anthracycline induced cardiac damage. These are not linearly related to anthracycline dose but appear to reflect the underlying myocardial pathophysiology associated with anthracycline toxicity, which is not demonstrated by the standard $M$ mode echocardiogram. Although the overall clinical significance of such diastolic dysfunction is uncertain, some individual abnormalities may have significant management and therapeutic implications.

(Br Heart f 1995;73:340-350)

Keywords: left ventricular diastolic function in children; Doppler echocardiography; anthracycline chemotherapy

It has been suggested that abnormalities of diastolic function may precede systolic decompensation in some cardiomyopathies, ${ }^{1}$ or may in some instances underlie symptomatic cardiac failure in the presence of relatively normal systolic function. ${ }^{23}$ Thus assessment of diastolic function in patients with, or at risk from, cardiac decompensation might permit detection of subclinical dysfunction and facilitate pre-emptive treatment, or might assist in optimisation of treatment along physiological lines. This is perhaps of particular relevance in children in whom global myocardial dysfunction is more common than the more focal abnormalities of ischaemic heart disease.

Anthracycline cardiomyopathy is an increasingly common problem among children and young adults in view of the high survival rates now achieved for childhood malignancies treated using anthracycline containing regimens. ${ }^{4}$ Using radionuclide angiography, Lee and coworkers ${ }^{5}$ demonstrated abnormalities of diastolic function in adults receiving cardiotoxic anthracycline agents as part of treatment for cancer at doses lower 
than those producing significant changes in systolic function. Similar results were noted by Hausdorf et $a l^{6}$ using computer assisted analysis of left ventricular (LV) wall motion. There is increasing interest in the use of Doppler echocardiographic assessment of transmitral flow patterns as a measure of $\mathrm{LV}$ diastolic function, ${ }^{7-10}$ although growth related data for normal children have only recently become available. ${ }^{11}$ Marchandise and coworkers $^{12}$ demonstrated abnormal transmitral Doppler flow patterns in adults with subclinical anthracycline cardiotoxicity and normal systolic function, as have the authors' own preliminary studies in children. ${ }^{13}$ The findings in adults cannot be directly extrapolated to children, however, and their significance in terms of long-term cardiac prognosis remains unclear.

LV diastolic function was therefore assessed in 226 patients treated with anthracyclines in childhood using Doppler echocardiography. The significance of the information obtained is examined in relation to their treatment, clinical status, and systolic LV function. Potential correlations with the underlying pathophysiology of anthracycline cardiotoxicity are also presented.

\section{Patients and methods}

\section{PATIENT AND TREATMENT DETAILS}

From examination of departmental records of patients previously treated in childhood for malignant disease, 236 patients were identified as having survived more than six months from initial exposure to anthracycline drugs. All patients who died from acute complications of their treatment, including a small number dying early from anthracycline cardiomyopathy, were therefore excluded.

Of 236 patients recalled for cardiovascular assessment, 226 attended-that is $96 \%$ ascertainment. There were 82 females and 144 males aged between 3.5 and 33 (median 12.1) years at the time of study.

Previous history was determined from detailed review of case notes. Cumulative anthracycline doses received ranged from 50 to 750 (median $300 \mathrm{mg} / \mathrm{m}^{2}$ of daunorubicin, doxorubicin (Adriamycin), or epirubicin, either singly or in combination. Some 137 patients had been treated for leukaemia or lymphoma and 89 for solid tumours. All patients had received other cytotoxic agents, the majority of which are not usually considered cardiotoxic. Two patients, however, had received mitozantrone, which may cause acute cardiotoxicity. In cases in which cyclophosphamide had been administered it was given at doses not normally considered to be cardiotoxic. Anthracycline had been administered by slow bolus injection; the maximum dose being $150 \mathrm{mg} / \mathrm{m}^{2}$, and the minimum dosing interval three weeks. Twenty two patients $(10 \%)$ had received mediastinal, thoracic, or craniospinal irradiation, in which some or all of the heart was incorporated in the radiation field.

The length of follow up was measured from first exposure to anthracyclines as several patients had received more than one course of anthracyclines. Median (range) time from first exposure to anthracycline was $5 \cdot 3$ years $(6 \cdot 5$ months- 17 years).

The 10 patients (4\%) who were not examined had no symptoms of cardiac dysfunction at their last clinical review. They had been treated between 1975 and 1985, with daunorubicin or adriamycin 90-450 (mean 261) $\mathrm{mg} / \mathrm{m}^{2}$ and were therefore generally representative of the rest of the study group.

\section{CARDIOLOGICAL ASSESSMENT}

Weight and height of all patients were recorded and body surface area (BSA) calculated using standard nomograms. Details of current and previous effort tolerance were noted together with any current medication. Full cardiovascular examination was performed by a paediatric cardiologist and supine blood pressure was recorded at I and V phase Korotkoff sounds.

Echocardiographic examination was performed in the left lateral semirecumbent position whenever possible and sedation was not used. Examinations were performed by a single operator (FAB) using a Hewlett Packard $77020 \mathrm{AC}$ ultrasound scanner and recorded onto videotape. An electrocardiographic trace and phonocardiogram were recorded simultaneously with the echocardiogram. Transducer frequency was $3.5 \mathrm{MHz}$ or $5 \mathrm{MHz}$, either or both being used for each patient. "Chart speed" was $100 \mathrm{~mm} / \mathrm{s}$ for all recordings.

Cross sectional imaging was performed from the standard parasternal, apical, and subcostal views to confirm the presence of normal cardiac anatomy. Transmitral flow velocity patterns were recorded from the apical four chamber view according to the methods described elsewhere. ${ }^{11} \mathrm{M}$ mode tracings were obtained from the parasternal long axis view at the junction of the mitral valve leaflet tips and the papillary muscles/chordae tendineae perpendicular to the $\mathrm{LV}$ endocardial surface of the interventricular septum. At least 20 cardiac cycles were recorded in each modality.

\section{ECHOCARDIOGRAPHIC ANALYSIS}

All scans were analysed by a single observer (FAB) from the previously recorded videotapes using the Hewlett Packard "off-line" analysis software.

Transmitral Doppler flow signals were analysed as described previously. ${ }^{11}$ The mean of $M$ mode measurements from the four cardiac cycles with maximal diastolic diameters for each patient was used for analysis. LV cavity and posterior wall dimensions were measured in centimetres by the "trailing edge-leading edge" method. LV diastolic diameter (LVDD) and posterior wall diastolic thickness (PWD) were measured at the point of maximum diastolic posterior deflection of the posterior wall. LV systolic diameter (LVDS) and posterior wall systolic thickness (PWS) were measured at the point of maximum anterior deflection of the posterior wall. 
Left ventricular shortening fraction (SF (\%)) was calculated from the formula:

$$
\mathrm{SF}=\frac{(\mathrm{LVDD}-\mathrm{LVDS})}{\mathrm{LVDD}} \times 100
$$

Fractional thickening of the posterior wall (TF (\%)) was calculated as:

$$
\mathrm{TF}=\frac{(\mathrm{PWS}-\mathrm{PWD})}{\mathrm{PWD}} \times 100
$$

CONTROL DATA

Data were compared with those of 137 healthy children and young adults examined by identical techniques, expressed as group median values for $0.2 \mathrm{~m}^{2}$ BSA intervals. The majority of these data are published elsewhere. ${ }^{11}$

\section{DATA ANALYSIS}

The principal hypothesis for analysis was that anthracycline treatment has long-term, dose related effects on $\mathrm{LV}$ diastolic function, and if proven, how this relates to symptomatology, systolic function, and underlying myocardial pathophysiology. Additional areas of interest were any relations with the effects of adjuvant radiotherapy and the effects of elapsed time from initial cardiac insult, with particular reference to myocardial growth.

Patients were therefore stratified by cumulative anthracycline dose at intervals of 100 $\mathrm{mg} / \mathrm{m}^{2}$. This produced six groups, of which the central four consisted of 46-49 patients each. Twenty three patients received anthracycline $\leqslant 100 \mathrm{mg} / \mathrm{m}^{2}$ and 12 anthracycline $>$ $500 \mathrm{mg} / \mathrm{m}^{2}$ (table 1 ).

Each case was compared with the median of the normal values lying in the same $0.2 \mathrm{~m}^{2}$ BSA interval using the paired Wilcoxon signed ranking test. Examination of data for factors influencing ventricular function required comparisons between subgroups with different BSA distributions. Com- parisons for BSA dependent variables were therefore performed directly and as a percentage of paired median control values using the Mann-Whitney $\mathrm{U}$ test. The $\chi^{2}$ test was used to examine the incidence of certain abnormalities, with Yates's correction for continuity when appropriate. Fisher's exact test was used for groups of 20 patients or less. Simple correlation and regression analyses were also used to examine interrelationships.

Numeric data are either displayed in graphic/tabular form or reported in the text as median (interquartile range). Other data not displayed are available from the authors on request. *

The p-values for the statistical comparisons illustrated in fig 2 have not been adjusted for the multiple comparisons which have been carried out.

Full ethical approval was given for the study by the Bristol and Weston District Ethical Committee. Informed consent for each study was obtained from all parents and from the patients where appropriate.

\section{Results}

SYMPTOMS

Eleven patients (5\%) had symptoms likely to relate to myocardial dysfunction. These ranged from complaints of undue fatigue on exercise to overt cardiac failure and pericarditic chest pain; four were receiving antifailure medication. Two had effort dyspnoea and fatigue sufficient to warrant classification within New York Heart Association Class $3,{ }^{14}$ the other symptomatic patients were in class 2. Five had survived cardiac failure or severe impairment of LV function soon after the end of treatment. All symptomatic patients had received anthracycline $>300$

${ }^{\star}$ (These data are available on request from the authors.)

\begin{tabular}{|c|c|c|c|c|c|c|}
\hline & \multicolumn{6}{|c|}{ Anthracycline $\left(\mathrm{mg} / \mathrm{m}^{2}\right)$} \\
\hline & $\leqslant 100$ & $101-200$ & $201-300$ & $301-400$ & $401-500$ & $>500$ \\
\hline Age (years) & $\begin{array}{l}10 \cdot 8 \\
(7 \cdot 8-14 \cdot 0)\end{array}$ & $\begin{array}{l}12 \cdot 0 \\
(7 \cdot 9-17 \cdot 2)\end{array}$ & $\begin{array}{l}11 \cdot 3 \\
(7 \cdot 6-16 \cdot 9)\end{array}$ & $\begin{array}{l}12 \cdot 6 \\
(10 \cdot 8-19 \cdot 3)\end{array}$ & $\begin{array}{l}13 \cdot 7 \\
(8 \cdot 6-18 \cdot 9)\end{array}$ & $\begin{array}{l}12 \cdot 8 \\
(10 \cdot 7-17 \cdot 7)\end{array}$ \\
\hline $\mathrm{BSA}\left(\mathrm{m}^{2}\right)$ & $\begin{array}{l}1 \cdot 13 \\
(0.9-1.4)\end{array}$ & $\begin{array}{l}1.31 \\
(0.93-1.73)\end{array}$ & $\begin{array}{l}1.29 \\
(0.89-1.59)\end{array}$ & $\begin{array}{l}1 \cdot 37 \\
(1 \cdot 1-1 \cdot 6)\end{array}$ & $\begin{array}{l}1.44 \\
(0.95-1.7)\end{array}$ & $\begin{array}{l}1.48 \\
(1 \cdot 1-1 \cdot 69)\end{array}$ \\
\hline Dose $\left(\mathrm{mg} / \mathrm{m}^{2}\right)$ & $\begin{array}{l}90 \\
(90)\end{array}$ & $\begin{array}{l}180 \\
(180-200)\end{array}$ & $\begin{array}{l}270 \\
(270-283)\end{array}$ & $\begin{array}{l}360 \\
(346-380)\end{array}$ & $\begin{array}{l}450 \\
(442-500)\end{array}$ & $\begin{array}{l}685 \\
(600-750)\end{array}$ \\
\hline $\begin{array}{l}\text { Age at first } \\
\text { treatment (years) } \\
\text { Time from first } \\
\text { treatment (years) }\end{array}$ & $\begin{array}{c}4 \cdot 43 \\
(2 \cdot 47-6 \cdot 72) \\
6 \cdot 85 \\
(3 \cdot 36-8 \cdot 7)\end{array}$ & $\begin{array}{c}7 \cdot 71 \\
(3 \cdot 79-12 \cdot 9) \\
4 \cdot 49 \\
(2 \cdot 46-5 \cdot 81)\end{array}$ & $\begin{array}{c}6 \cdot 25 \\
(3 \cdot 12-9 \cdot 82) \\
4 \cdot 53 \\
(2 \cdot 81-8 \cdot 45)\end{array}$ & $\begin{array}{c}5 \cdot 58 \\
(2 \cdot 58-8 \cdot 93) \\
8 \cdot 69 \\
(4 \cdot 52-10 \cdot 5)\end{array}$ & $\begin{array}{c}6 \cdot 09 \\
(3 \cdot 41-10 \cdot 9) \\
5 \cdot 6 \\
(3 \cdot 1-10 \cdot 6)\end{array}$ & $\begin{array}{l}7 \cdot 52 \\
(6 \cdot 35-10 \cdot 0) \\
4 \cdot 61 \\
(3.67-6.92)\end{array}$ \\
\hline $\begin{array}{l}\mathrm{BP} \\
\mathrm{S}(\mathrm{mm} \mathrm{Hg}) \\
\mathrm{BP} \\
\mathrm{D}(\mathrm{mm} \mathrm{Hg}) \\
\mathrm{Sex}(\mathrm{M} / \mathrm{F})\end{array}$ & $\begin{array}{l}93 \\
(90-110) \\
60 \\
(60-70) \\
15 / 8\end{array}$ & $\begin{array}{l}100 \\
(90-110) \\
65 \\
(60-70) \\
33 / 15\end{array}$ & $\begin{array}{l}100 \\
(90-110) \\
65 \\
(60-70) \\
28 / 20\end{array}$ & $\begin{array}{l}100 \\
(95-110) \\
70 \\
(60-70) \\
30 / 19\end{array}$ & $\begin{array}{l}110 \\
(95-110) \\
70 \\
(60-70) \\
30 / 16\end{array}$ & $\begin{array}{l}108 \\
(95 \cdot 118) \\
68 \\
(60-70) \\
8 / 4\end{array}$ \\
\hline $\begin{array}{l}\text { No of irradiated } \\
\text { patients }\end{array}$ & 1 & 1 & 5 & 7 & 5 & 3 \\
\hline $\begin{array}{l}\text { No of patients with } \\
\text { symptoms } \\
\text { No of patients with }\end{array}$ & 0 & 0 & 0 & 3 & 7 & 1 \\
\hline $\begin{array}{l}\text { shortening traction } \\
<30 \% \\
30-34 \% \\
\geqslant 35 \% \\
\text { Total no }\end{array}$ & $\begin{array}{r}0 \\
11 \\
12 \\
23\end{array}$ & $\begin{array}{r}2 \\
17 \\
29 \\
48\end{array}$ & $\begin{array}{r}6 \\
16 \\
26 \\
48\end{array}$ & $\begin{array}{l}15 \\
21 \\
13 \\
49\end{array}$ & $\begin{array}{r}21 \\
17 \\
8 \\
46\end{array}$ & $\begin{array}{r}7 \\
3 \\
2 \\
12\end{array}$ \\
\hline
\end{tabular}

Table 1 Clinical and treatment details for patients stratified by anthracycline dose 


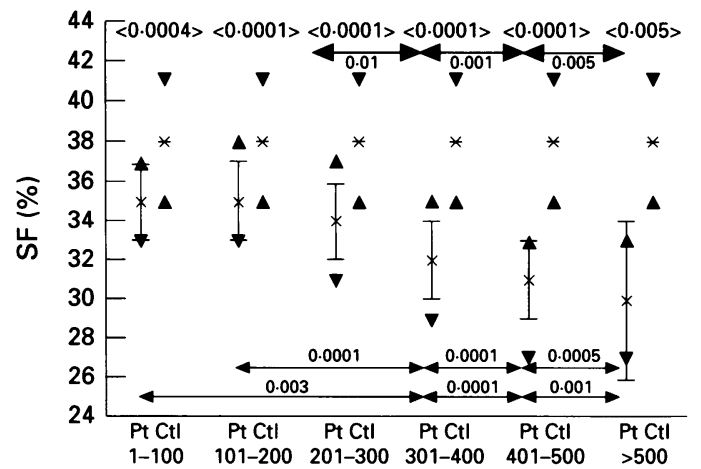

A Anthracycline dose range $\left(\mathrm{mg} / \mathrm{m}^{2}\right)$

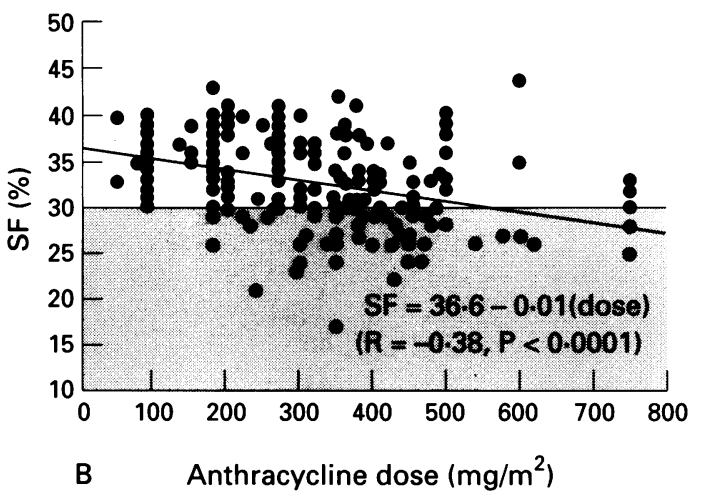

Figure 1(A) Data plot showing left ventricular shortening fraction (SF) grouped by cumulative anthracycline dose, with paired median body surface area (BSA) adjusted control (Ctl) values plotted adjacent to the study (Pt) values for each dose group. The outer arrows represent the interquartile range for each dose group. The error bars show the upper and lower confidence limits of the mean. $\langle\ldots\rangle$, relevant $P$ values between patients and matched BSA adjusted controls (paired Wilcoxon signed ranking test); $\stackrel{\cdots}{\longrightarrow}$, relevant $P$ values between dose groups (compared as percentages of paired $B S A$ adjusted control values) (Mann-Whitney U test). (B) Scatter plot of left ventricular SF for each patient $(n=226)$ against cumulative anthracycline dose, with the simple regression line and regression equation superimposed. $R$ is $P$ earson's correlation coefficient.

$\mathrm{mg} / \mathrm{m}^{2}$ between $2 \cdot 0$ and 13.0 (mean $7 \cdot 2$ ) years previously. Six (55\%) of these 11 patients had also received irradiation.

\section{BLOOD PRESSURE}

Systolic blood pressure was within normal limits for all patients, being between 80 and 120 (median 100) $\mathrm{mm} \mathrm{Hg}$, while diastolic pressure ranged from 30 to 100 (median 65) $\mathrm{mm} \mathrm{Hg}$. One patient taking antihypertensive doses of captopril had blood pressure of $110 / 90 \mathrm{~mm} \mathrm{Hg}$. Patients who had received anthracycline $\leqslant 200 \mathrm{mg} / \mathrm{m}^{2}$ had blood pressures similar to those of the controls while those who had received higher doses differed from the controls with respect to systolic blood pressure $(P<0.03)$.

\section{ECHOCARDIOGRAPHIC FINDINGS \\ Systolic function}

SF was reduced even at anthracycline doses $<100 \mathrm{mg} / \mathrm{m}^{2}$ (fig 1 (A)) compared with that of the controls (35 (33-37) v 38 (35-41), $\mathrm{P}=$ $0.0004)$, although there was little difference in cavity dimensions. Systolic and diastolic dimensions were significantly increased relative to those of the controls at higher doses ( $P$ $\leqslant 0.03)$ and there was a progressive increase in systolic dimension. Thus SF decreased

Table 2 Clinical and treatment details for patients stratified by shortening fraction

\begin{tabular}{lccc}
\hline & \multicolumn{3}{l}{ Shortening fraction (\%) } \\
\cline { 2 - 4 } & $<30$ & $30-34$ & 35 \\
\hline Anthracycline dose $\left(\mathrm{mg} / \mathrm{m}^{2}\right)$ & 424 & 300 & 265 \\
& $(360-465)$ & $(185-400)$ & $(180-320)$ \\
Age (years) & $17 \cdot 7$ & $11 \cdot 95$ & $10 \cdot 8$ \\
& $(12 \cdot 6-21 \cdot 3)$ & $(7 \cdot 5-15 \cdot 4)$ & $(8 \cdot 0-16 \cdot 6)$ \\
BSA (m $\left.{ }^{2}\right)$ & $1 \cdot 58$ & $1 \cdot 27$ & $1 \cdot 18$ \\
& $(1 \cdot 3-1 \cdot 75)$ & $(0 \cdot 92-1 \cdot 55)$ & $(0 \cdot 9-1 \cdot 56)$ \\
Age at first treatment & $8 \cdot 3$ & $5 \cdot 0$ & $5 \cdot 8$ \\
(years) & $(4 \cdot 35-11 \cdot 7)$ & $(3 \cdot 1-9 \cdot 13)$ & $(2 \cdot 69-10 \cdot 1)$ \\
Time from first treatment & $9 \cdot 2$ & $4 \cdot 6$ & $4 \cdot 62$ \\
(years) & $(5 \cdot 2-11 \cdot 9)$ & $(2 \cdot 9-8 \cdot 7)$ & $(2 \cdot 48-6 \cdot 6)$ \\
Sex (M/F) & $32 / 19$ & $54 / 31$ & $58 / 32$ \\
No of irradiated patients & 9 & 8 & 5 \\
No of patients with symptoms & 8 & 3 & 0 \\
Total no & 51 & 85 & 90 \\
\hline
\end{tabular}

Values are median (interquartile range). overall with increasing dose (fig $1(\mathrm{~B})$ ) and was inversely correlated with cumulative anthracycline dose with Pearson's correlation coefficient $(r)=-0.38(\mathbf{P}<0.0001)$.

From the authors' control data, a SF of $30 \%$ represents the lowest limit of normal, the 10 th centile value is $34 \%$ and the 25 th centile value $35 \%$. Fifty one patients had abnormal SF $(<30 \%), 85$ borderline SF (30-34\%), and 90 were within normal limits $(\geqslant 35 \%)$. Differences in SF between these patients are largely the result of differences in systolic rather than diastolic LV diameter. Clinical details are shown in table 2.

\section{Wall thickness}

Systolic posterior wall thickness was reduced relative to that of the controls even after low anthracycline doses $(1.04(0.92-1.27)$ v 1.19 $(1.03-1.51), P=0.0001$ at $\left.101-200 \mathrm{mg} / \mathrm{m}^{2}\right)$. The magnitude of the reduction of systolic wall thickness (and therefore of fractional thickening) increased with cumulative dose $(P \leqslant 0.03)$. A reduction in diastolic wall thickness compared with that of control values was apparent only at the highest anthracycline doses $(0.64(0.59-0.72) v 0.7$ $(0.63-0.81), P=0.07)$ but was more noticeable (relative to that of the controls) in those patients with the lowest $S F(P=0 \cdot 04)$.

\section{Heart rate}

Heart rate was normal in patients treated with anthracycline $<200 \mathrm{mg} / \mathrm{m}^{2}$, but tended to be faster than controls at higher doses (table 3 ). This difference was significant $(P \leqslant 0.03)$ only for patients who received 301-400 $\mathrm{mg} / \mathrm{m}^{2}$ or $>500 \mathrm{mg} / \mathrm{m}^{2}$ and there was no linear relationship with dose on regression analysis. Heart rate was also related to systolic functional status (table 4) being significantly greater than controls for those with the lowest SF $(P=0.002)$ but not for those with SF $\geqslant$ $30 \%$. Patients with SF $<30 \%$ had a much faster heart rate than those with $\mathrm{SF} \geqslant 30 \%$ $(110(95-122) v 101(89-112) \%$ of controls, $\mathrm{P}=0 \cdot 0007)$. 
Table 3 Diastolic function: relation with anthracycline dose

\begin{tabular}{|c|c|c|c|c|c|c|}
\hline & \multicolumn{6}{|c|}{ Anthracycline dose group $\left(\mathrm{mg} / \mathrm{m}^{2}\right)$} \\
\hline & $\leqslant 100$ & $101-200$ & $201-300$ & $301-400$ & $401-500$ & $>500$ \\
\hline $\begin{array}{l}\text { Anthracycline dose } \\
\left(\mathrm{mg} / \mathrm{m}^{2}\right)\end{array}$ & $\begin{array}{c}90 \\
(90)\end{array}$ & $\begin{array}{l}180 \\
(180-200)\end{array}$ & $\begin{array}{l}270 \\
(270-283)\end{array}$ & 360 & 450 & 685 \\
\hline HR & 74 & 81 & 88 & $\begin{array}{l}(340-300) \\
85\end{array}$ & $\begin{array}{r}442- \\
86\end{array}$ & $\begin{array}{r}1000- \\
88\end{array}$ \\
\hline (beats/min ${ }^{-1}$ ) & $(66-95)$ & (72-93) & $(76-100)$ & $(76-92)$ & $(76-99)$ & $(73-96)$ \\
\hline${ }^{\mathrm{E}}\left(\mathrm{ms}^{-1}\right.$ & $\begin{array}{l}0.82 \\
(0.77-0.88)\end{array}$ & $\begin{array}{l}0.83 \\
(0.75-0.91)\end{array}$ & $\begin{array}{l}0.8 \\
(0.72-0.9)\end{array}$ & $\begin{array}{l}0.8 \\
(0.71-0.86)\end{array}$ & $\begin{array}{l}0.77 \\
(0.68-0.82)\end{array}$ & $\begin{array}{l}0 \cdot 82 \\
(0 \cdot 7-0.93)\end{array}$ \\
\hline $\mathrm{A}_{\left(\mathrm{ms}^{-1}\right)}$ & $\begin{array}{l}0.48 \\
(0.39-0.52)\end{array}$ & $\begin{array}{l}0.48 \\
(0.4-0.56)\end{array}$ & $\begin{array}{l}0.55 \\
\quad(0.44-0.62)\end{array}$ & $\begin{array}{l}0.48 \\
(0.43-0.56)\end{array}$ & $\begin{array}{l}0.49 \\
(0.42-0.59)\end{array}$ & $\begin{array}{l}0.53 \\
(0.46-0.61)\end{array}$ \\
\hline EA & 1.85 & 1.73 & 1.52 & 1.6 & 1.44 & 1.59 \\
\hline & $(1 \cdot 57-2 \cdot 03)$ & $1 \cdot 48-2 \cdot 11)$ & $(1 \cdot 25-1 \cdot 76)$ & $(1 \cdot 37-1 \cdot 77)$ & $(1 \cdot 26-1 \cdot 87)$ & $(1 \cdot 17-1 \cdot 94)$ \\
\hline $\begin{array}{r}\text { EAccT } \\
(\mathrm{ms})\end{array}$ & $\begin{array}{l}77 \\
(68-81)\end{array}$ & $\begin{array}{l}76 \\
(71-86)\end{array}$ & $\begin{array}{l}78 \\
(73-82)\end{array}$ & $\begin{array}{l}76 \\
(72-79)\end{array}$ & $\begin{array}{l}81 \\
(72-84)\end{array}$ & $\begin{array}{l}77 \\
(71-84)\end{array}$ \\
\hline $\begin{array}{l}\text { EAcc } \\
\left(\mathrm{ms}^{-2}\right)\end{array}$ & $\begin{array}{l}11 \cdot 3 \\
(9 \cdot 9-12 \cdot 7)\end{array}$ & $\begin{array}{l}10 \cdot 8 \\
(9 \cdot 13-12 \cdot 6)\end{array}$ & $\begin{array}{l}10 \cdot 6 \\
(9 \cdot 19-11 \cdot 8)\end{array}$ & $\begin{array}{l}10 \cdot 5 \\
(9 \cdot 06-12 \cdot 0)\end{array}$ & $\begin{array}{l}9 \cdot 45 \\
(8 \cdot 62-11 \cdot 6)\end{array}$ & $\begin{array}{l}10 \cdot 4 \\
(9 \cdot 31-12 \cdot 7)\end{array}$ \\
\hline $\begin{array}{r}\text { EDecT } \\
(\mathrm{ms})\end{array}$ & 117 & 119 & 116 & 122 & 117 & 119 \\
\hline EDec & $\begin{array}{l}09-124 \\
7 \cdot 37\end{array}$ & $\begin{array}{c}(101-133 \\
6.98\end{array}$ & $\begin{array}{c}(105-127 \\
6.85\end{array}$ & $\begin{array}{c}(110-13 \\
6 \cdot 42\end{array}$ & $\begin{array}{c}(103-126 \\
6.56\end{array}$ & $\begin{array}{c}(111-131) \\
6.94\end{array}$ \\
\hline$\left(\mathrm{ms}^{-2}\right)$ & $(6 \cdot 56-8 \cdot 44)$ & $(6 \cdot 45-8 \cdot 16)$ & $(6 \cdot 35-7 \cdot 92)$ & $(5 \cdot 82-7 \cdot 4)$ & $(5 \cdot 58-7 \cdot 76)$ & $(5 \cdot 81-8 \cdot 45)$ \\
\hline $\begin{array}{l}\text { EVI } \\
(\mathrm{cm})\end{array}$ & $\begin{array}{l}8 \cdot 34 \\
(8 \cdot 02-9 \cdot 13)\end{array}$ & $\begin{array}{l}8 \cdot 55 \\
(7 \cdot 68-9 \cdot 65)\end{array}$ & $\begin{array}{l}8 \cdot 22 \\
(7 \cdot 15-9 \cdot 46)\end{array}$ & $\begin{array}{l}8 \cdot 26 \\
(7 \cdot 47-8 \cdot 89)\end{array}$ & $\begin{array}{l}8 \cdot 19 \\
(7 \cdot 06-8 \cdot 89)\end{array}$ & $\begin{array}{c}8 \cdot 32 \\
(7 \cdot 55-9 \cdot 36)\end{array}$ \\
\hline AVI & $3 \cdot 22$ & $3 \cdot 11$ & 3.56 & $\begin{array}{c}(7 \cdot 47 \\
3.4\end{array}$ & $\begin{array}{r}7 \cdot 06- \\
3 \cdot 54\end{array}$ & $\begin{array}{l}(7.55-9 \cdot 36) \\
3.66\end{array}$ \\
\hline$(\mathrm{cm})$ & $(2 \cdot 84-3 \cdot 73)$ & $(2 \cdot 62-3.92)$ & $(2 \cdot 97-4 \cdot 06)$ & $(2 \cdot 87-3 \cdot 8)$ & $(3 \cdot 0-4 \cdot 05)$ & $(2 \cdot 98-4 \cdot 4)$ \\
\hline VIR & 0.71 & 0.7 & 0.67 & 0.69 & 0.68 & 0.67 \\
\hline VRT & 60 & 55 & $\begin{array}{l}(0 \cdot \\
58\end{array}$ & $\begin{array}{l}(0 . \\
59\end{array}$ & $0 \cdot 73)$ & $-0 \cdot 75)$ \\
\hline$(\mathrm{n}$ & $(54-65)$ & $(50-67)$ & $(51-67)$ & $(51-64)$ & $(48-66)$ & $(43-67)$ \\
\hline Total no & 23 & 48 & 48 & 49 & 46 & 12 \\
\hline
\end{tabular}

Values are median (interquartile range). $\mathrm{HR}$, heart rate (beats $\left./ \mathrm{min}^{-1}\right) ; \mathrm{E}$, peak early phase filling velocity ( $\left.\mathrm{ms}^{-1}\right) ; \mathrm{A}$, peak atrial phase filling velocity $\left(\mathrm{ms}^{-1}\right)$; EA, EA ratio (E/A); EAccT, time to peak E (ms); EAcc, acceleration to peak E (ms $\left.{ }^{-2}\right)$; EDecT, time phase filling velocity $\left(\mathrm{ms}^{-1}\right)$; EA, EA ratio (E/A); EAccT, time to peak E (ms); EAcc, acceleration to peak E (ms $\left.\mathrm{m}^{-2}\right)$; EDecT, time
from peak $\mathrm{E}$ to baseline (ms); EDec, deceleration from peak $\mathrm{E}\left(\mathrm{ms}^{-2}\right)$; EVI, velocity integral of E wave (cm); AVI, velocity integral from peak E to baseline (ms); EDec, deceleration from peak E ( $\left.\mathrm{ms}^{-2}\right)$; EVI, velocity integral of E wave (cm); AVI, velocity integral of A wave (ch

\section{Diastolic function}

Diastolic filling patterns also varied with cumulative anthracycline dose, but in a more complex manner (figs $2(\mathrm{~A})-2(\mathrm{E})$ and table 3).

There was no significant difference in heart rate or any diastolic filling parameter between controls and patients who received anthracycline $\leqslant 100 \mathrm{mg} / \mathrm{m}^{2}$.

In patients given anthracycline 101-200 $\mathrm{mg} / \mathrm{m}^{2}$ acceleration to peak early phase filling velocity (EACC) did not differ from that of the controls but acceleration time was prolonged $(P=0.07)$ and peak early phase filling velocity $(E)$ mildly increased. Heart rate was similar to that of the control values and

Table 4 Diastolic function: relation with shortening fraction

\begin{tabular}{|c|c|c|c|}
\hline \multirow{3}{*}{$\begin{array}{l}\text { Anthracycline dose } \\
\left(\mathrm{mg} / \mathrm{m}^{2}\right) \\
\mathrm{HR} \\
\left.\text { (beats } \mathrm{min}^{-1}\right)\end{array}$} & \multicolumn{3}{|c|}{ Shortening fraction (\%) } \\
\hline & $\begin{array}{l}424 \\
(360-465)\end{array}$ & $\begin{array}{l}300 \\
(185-400)\end{array}$ & $\begin{array}{l}265 \\
(180-320)\end{array}$ \\
\hline & $\begin{array}{l}87 \\
(76-95)\end{array}$ & $\begin{array}{l}84 \\
(71-93)\end{array}$ & $\begin{array}{l}85 \\
(73-94)\end{array}$ \\
\hline $\mathrm{E}\left(\mathrm{ms}^{-1}\right)$ & $\begin{array}{c}0.72 \\
(0.62-0.8)\end{array}$ & $\begin{array}{l}0.79 \\
(0.72-0.9)\end{array}$ & $\begin{array}{l}0.83 \\
(0.78-0.9)\end{array}$ \\
\hline $\mathrm{A}_{\left(\mathrm{ms}^{-1}\right)}$ & $\begin{array}{l}0.49 \\
(0.42-0.59)\end{array}$ & $\begin{array}{l}0.5 \\
(0.39-0.58)\end{array}$ & $\begin{array}{l}0.49 \\
(0.42-0.56)\end{array}$ \\
\hline EA & $\begin{array}{l}1 \cdot 37 \\
(1 \cdot 2-1 \cdot 7)\end{array}$ & $\begin{array}{l}1 \cdot 61 \\
(1 \cdot 36-2 \cdot 0)\end{array}$ & $\begin{array}{l}1 \cdot 71 \\
(1.42-1.96)\end{array}$ \\
\hline $\begin{array}{r}\text { EAccT } \\
(\mathrm{ms})\end{array}$ & $\begin{array}{l}78 \\
(72-85)\end{array}$ & $\begin{array}{l}76 \\
(70-82)\end{array}$ & $\begin{array}{l}76 \\
(70-83)\end{array}$ \\
\hline $\begin{array}{l}\mathrm{EAcc} \\
\left(\mathrm{ms}^{-2}\right)\end{array}$ & $\begin{array}{l}9 \cdot 18 \\
(7 \cdot 58-10 \cdot 4)\end{array}$ & $\begin{array}{l}10 \cdot 7 \\
(9 \cdot 29-12 \cdot 3)\end{array}$ & $\begin{array}{l}11 \cdot 2 \\
(9 \cdot 45-12 \cdot 2)\end{array}$ \\
\hline $\begin{array}{r}\text { EDecT } \\
(\mathrm{ms})\end{array}$ & $\begin{array}{l}119 \\
(109-134)\end{array}$ & $\begin{array}{l}119 \\
(105-132)\end{array}$ & $\begin{array}{l}116 \\
(103-126)\end{array}$ \\
\hline $\begin{array}{l}\mathrm{EDec} \\
\left(\mathrm{ms}^{-2}\right)\end{array}$ & $\begin{array}{l}6 \cdot 14 \\
(5 \cdot 34-6 \cdot 57)\end{array}$ & $\begin{array}{l}6 \cdot 91 \\
(6 \cdot 17-7 \cdot 81)\end{array}$ & $\begin{array}{l}7 \cdot 27 \\
(6 \cdot 51-8 \cdot 47)\end{array}$ \\
\hline $\begin{array}{l}\text { EVI } \\
(\mathrm{cm})\end{array}$ & $\begin{array}{l}7 \cdot 62 \\
(6 \cdot 57-8 \cdot 8)\end{array}$ & $\begin{array}{l}8 \cdot 29 \\
(7 \cdot 59-9 \cdot 21)\end{array}$ & $\begin{array}{l}8 \cdot 55 \\
(7 \cdot 77-9 \cdot 76)\end{array}$ \\
\hline AVI & $\begin{array}{l}3 \cdot 6 \\
(3 \cdot 06-4 \cdot 16)\end{array}$ & $\begin{array}{l}3.43 \\
(2 \cdot 86-3.92)\end{array}$ & $\begin{array}{l}3 \cdot 3 \\
(2 \cdot 78-4 \cdot 04)\end{array}$ \\
\hline VIR & $\begin{array}{l}0.67 \\
(0.63-0.71)\end{array}$ & $\begin{array}{l}0.69 \\
(0.65-0.73)\end{array}$ & $\begin{array}{l}0.69 \\
(0.65-0.73)\end{array}$ \\
\hline $\begin{array}{l}\text { IVRT } \\
(\mathrm{ms})\end{array}$ & $\begin{array}{l}63 \\
(54-74)\end{array}$ & $\begin{array}{l}58 \\
(50-65)\end{array}$ & $\begin{array}{l}55 \\
(49-62)\end{array}$ \\
\hline Total no & 51 & 85 & 90 \\
\hline
\end{tabular}

Values are median (interquartile range). Key as given for Table 3. although the peak early phase filling velocity/peak atrial filling velocity (EA) ratio was increased, the difference was not statistically significant.

In patients who had been given anthracycline $201-300 \mathrm{mg} / \mathrm{m}^{2}$ peak atrial phase filling velocity (A) was increased, as was heart rate. Acceleration time was prolonged despite the increased heart rate $(P=0.02)$, so that peak $E$ velocity and $E$ velocity integral remained similar to those of the control values. Deceleration time was shorter, A velocity integral increased, and the velocity integral ratio reduced $(P=0.0001)$.

In the group who had received anthracycline between 301 and $400 \mathrm{mg} / \mathrm{m}^{2}$ heart rate was similar to that of the controls, but atrial filling remained increased (A raised and velocity integral ratio reduced). Acceleration to and deceleration from peak $\mathrm{E}$ were reduced $(P \leqslant 0.01)$, but early filling time was similar to that of the control values.

In patients who had received anthracycline $401-500 \mathrm{mg} / \mathrm{m}^{2}$ the reduction of acceleration to peak $\mathrm{E}$ compared with that of the controls was more marked $(P=0.003)$, heart rate increased, and peak $\mathrm{E}$ velocity reduced. The rate and time of deceleration from peak $E$ velocity were reduced, peak A velocity increased and EA ratio reduced. With a reduction in early filling time and rate, $\mathrm{E}$ velocity integral was also reduced, and the velocity integral ratio was therefore also less than the controls.

Peak A velocity remained increased at anthracycline doses $>500 \mathrm{mg} / \mathrm{m}^{2}$. There was a tendency for prolongation of isovolumic relaxation time (IVRT) at higher doses $(>500$ $\left.\mathrm{mg} / \mathrm{m}^{2} v 1-100 \mathrm{mg} / \mathrm{m}^{2}, \mathrm{P}=0.06\right)$, but differences from control values did not reach statistical significance at any dose. 

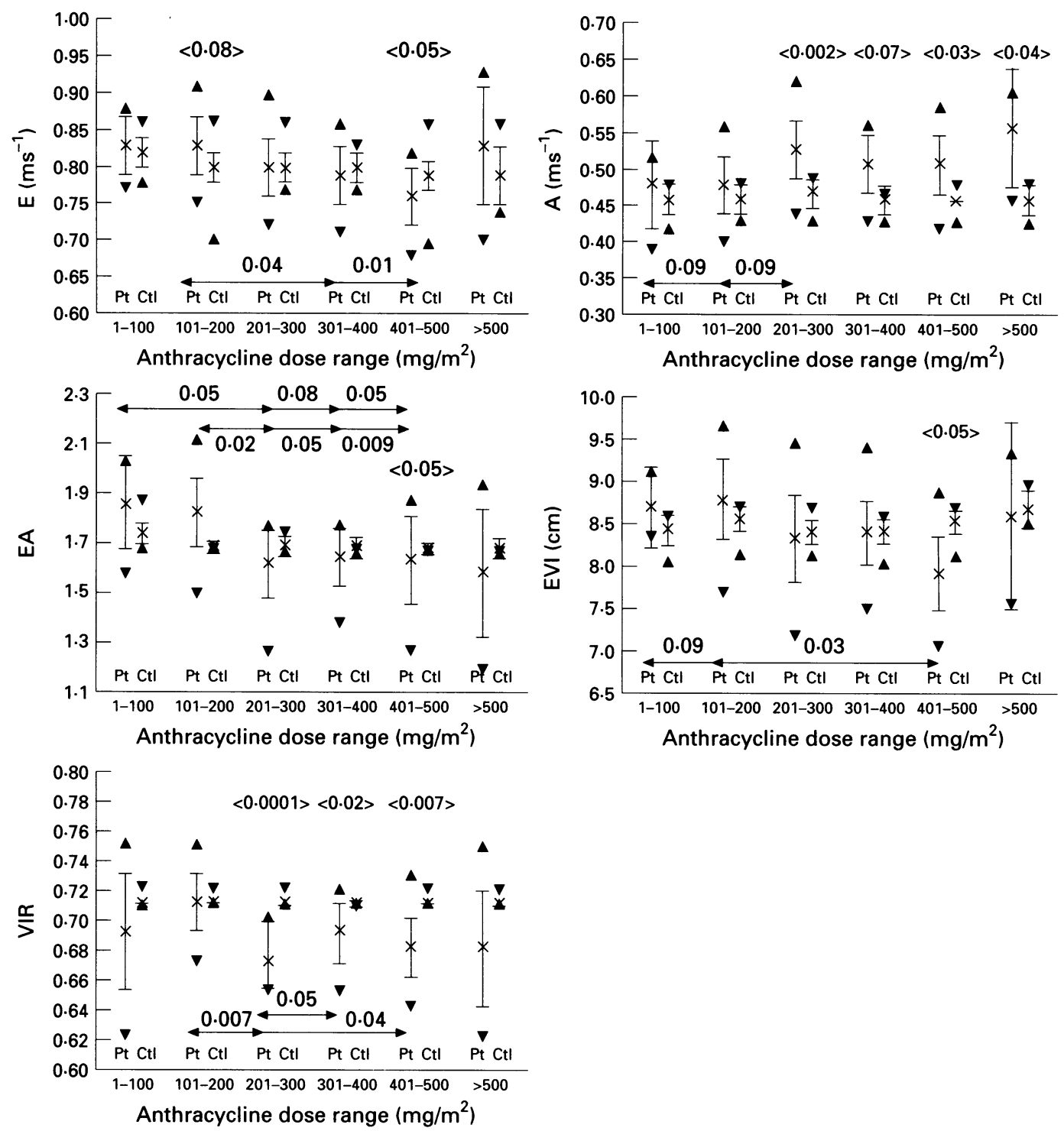

Figure 2 Data plots representing the principal long-term effects of anthracycline treatment on heart rate and diastolic cardiac function, plotted in groups according to cumulative anthracycline dose, with paired median body surface area $(B S A)$ adjusted control (Ctl) values plotted adjacent to the study $\left(P_{t}\right)$ values for each dose group. The outer arrows represent the inter quartile range for each dose group. The error bars show the upper and lower confidence limits of the mean. $\langle\ldots$.$\rangle , relevant p-values between patients and matched BSA adjusted controls (paired Wilcoxon signed ranking$ test); $\longleftrightarrow$, relevant p-values between dose groups (compared as percentages of paired BSA adjusted control values) (Mann-Whitney $U$ test)). E, peak early phase filling velocity $\left(m s^{-1}\right) ; A$, peak atrial phase filling velocity $\left(m s^{-1}\right) ; E A$, $E A$ ratio $(E / A) ; E V I$, velocity integral of $E$ wave $(\mathrm{cm}) ; V I R$, velocity integral ratio $(E V I / v e l o c i t y$ integral of entire transmitral flow complex $(\mathrm{cm})$.

Relation between diastolic and systolic function Examination of diastolic filling patterns in relation to LV SF allows further insight into the changes in diastolic function associated with anthracycline induced myocardial damage (table 4).

Patients with the lowest SF show marked differences in diastolic filling from those of the controls. Acceleration to peak $\mathrm{E}$ was reduced $(P=0.0005)$, with deceleration rate and time also lower than controls $(P=0.06$ and 0.009 respectively), and IVRT prolonged compared with that in patients with $\mathrm{SF}>30 \%$ ( $\mathbf{P}=$ $0.04)$ and the controls $(P=0.07)$. Thus there is much less opportunity for passive early diastolic filling, the $\mathrm{E}$ velocity integral is also reduced $(P<0.001)$, peak $A$ velocity and velocity integral of $A$ wave increased $(P \leqslant$ $0.03)$ and the velocity integral ratio reduced $(\mathbf{P}=<0.0001)$.
Patients with SF within the normal range also showed abnormalities of diastolic function but these were different from those in patients with $\mathrm{SF}<30 \%$. Peak $\mathrm{E}$ velocity was increased $(P=0.04)$, with a relatively shorter IVRT $(P=0.04$ for patients with $S F \geqslant v$ those with $\mathrm{SF}<35 \%$ ), prolonged acceleration time $(P=0.006)$ and normal acceleration to peak $E$. There was a tendency for deceleration rate and time to be reduced, so the $\mathrm{E}$ velocity integral was only marginally increased, peak $A$ velocity was also increased (despite normal heart rate), and the EA ratio was similar to that of the controls. The A velocity integral was also similar to that of the controls, but the velocity integral ratio was reduced $(P=0.03)$.

Mitral inflow patterns in patients with borderline SF were between these groups. Isovolumic relaxation and $\mathrm{E}$ acceleration times were similar to those of control values 
so that although acceleration to peak $\mathrm{E}$ was reduced $(P=0.05)$, peak $E$ velocity and $E$ velocity integral were similar to those of controls. Peak A velocity was increased $(P=$ 0.04 ) despite normal heart rate and although EA ratio and A velocity integral were similar to those of controls, the velocity integral ratio was reduced $(P=0.01)$.

\section{RELATIONS BETWEEN DIASTOLIC FUNCTION} AND THE INCIDENCE OF SYMPTOMATIC HEART FAILURE OR REDUCED SF

Different patterns of diastolic filling are clearly associated with different degrees of anthracycline induced myocardial damage; their potential relations with underlying pathophysiology are explored in the discussion. It is also pertinent, however, to examine whether specific abnormalities of diastolic function might identify individuals with or at particular risk of systolic decompensation. The incidence of symptoms and abnormal SF increases fairly uniformly with incremental dose group (table $1, P<0.005, \chi^{2}$ test), but it appears that there is much more individual variability in diastolic functional response. Although normal values of many diastolic filling variables alter with BSA, ${ }^{11}$ there is little change in peak $\mathrm{E}$ and $\mathrm{A}$ velocities, EA ratio, and acceleration to and deceleration from peak $E$ for BSAs $>0.8 \mathrm{~m}^{2}$. As the majority of patients in this study had BSAs $>0.8 \mathrm{~m}^{2}$, it was possible to examine the incidence of symptoms or reduced SF, or both, in patients with values of these diastolic variables outside the 10th and 90th centile values for BSA $>$ $0.8 \mathrm{~m}^{2}$. These comprised for $\mathrm{E}:<0.68 \mathrm{~ms}^{-1}$ and $>0.96 \mathrm{~ms}^{-1}$; for A: $<0.36 \mathrm{~ms}^{-1}$ and $>$ $0.62 \mathrm{~ms}^{-1}$; for EA: $<1.38$ and $>2.36$; for EAcc: $<6.0 \mathrm{~ms}^{-2}$ and $>14.5 \mathrm{~ms}^{-2}$; and for EDec (EDec): $<4.0 \mathrm{~ms}^{2}$ and $>10.5 \mathrm{~ms}^{-2}$.

A low peak $E$ velocity was associated with reduced $S F(P=0.0007)$ as was a lower EA ratio $(P=0.01)$, and eight of the 11 symptomatic patients had an outlying EA ratio ( $P=$ $0.05)$. These associations, however, were not predictive and there were no readily discernible associations with peak A velocity, EAcc, or EDec.

Examining extremes of variable distribution, it is interesting that at anthracycline doses $>300 \mathrm{mg} / \mathrm{m}^{2}$, of the nine patients with an EA ratio $>90$ th centile, only the two with the highest EA ratios $(4.3$ and 3.3 respectively) were overtly symptomatic, although five patients had an EA ratio $\geqslant 3 \cdot 0$. One of eight patients with an EA ratio $<1.0$ was symptomatic. No patient with a high peak A velocity was symptomatic but two of six with $A<0.3 \mathrm{~ms}^{-1}$ had heart failure. One patient with $A=0.32$ was also symptomatic. Thus patients with a very low A or very high EA ratio seem more likely to be symptomatic, but there are also patients with abnormal filling patterns who are apparently symptom free.

There were no direct relations apparent between any variable of diastolic filling and posterior wall dimensions or fractional thickening, although it has already been noted that

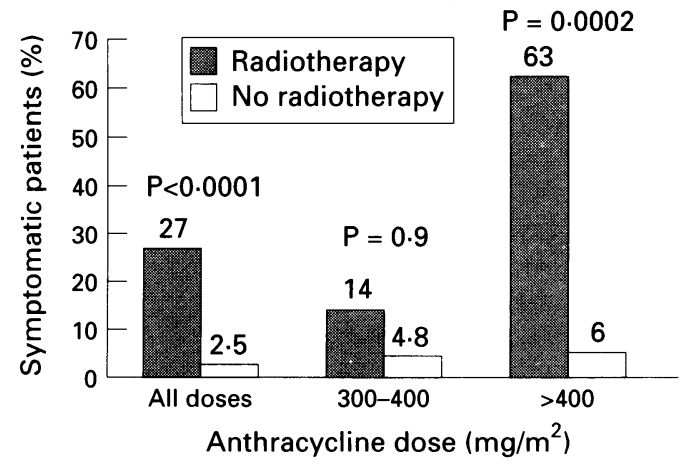

Figure 3 Histogram showing the percentage of symptomatic patients overall and grouped for anthracycline doses according to irradiation status. P-Values are indicative of the relation between symptomatology and irradiation status ( $\chi^{2}$ test).

certain abnormalities of diastolic filling are associated with reduced SF when posterior wall thickness is also reduced.

\section{EFFECTS OF IRRADIATION}

Five $(45 \%)$ of the eleven symptomatic patients had received irradiation. This is a much higher proportion than would be expected from the whole group $(22(<10 \%)$ of 226). Six (40\%) of the 15 patients who received irradiation with anthracycline $>300$ $\mathrm{mg} / \mathrm{m}^{2}$ were symptomatic compared with five $(5 \%)$ of 92 given the same dose without radiotherapy. The overall risk of symptoms from anthracycline treatment is increased more than 10 -fold by cardiac irradiation $(\mathrm{P}<$ $0.0001)$ and increases with anthracycline dose such that $>60 \%$ of those given $>400 \mathrm{mg} / \mathrm{m}^{2}$ and radiotherapy had symptomatic dysfunction (fig 3).

Although some reduction in SF was also associated with irradiation (nine $(41 \%)$ of 22 irradiated patients had SF $<30 \%$ compared with $42(21 \%)$ of $204, P=0.06)$, this difference was much less marked than expected from the incidence of symptomatic cardiac failure. LV systolic and diastolic diameters were significantly smaller (as a percentage of control) in the six symptomatic patients who received radiotherapy compared with the five who did not $(P<0.05)$, but there were no detectable differences in wall thickness. Similarly, LV cavity dimensions were lower in the nine irradiated patients with $\mathrm{SF}<30 \%$ than the 42 who did not receive radiotherapy $(\mathrm{P}<0.05)$.

Both patients with symptomatic cardiac dysfunction and a high EA ratio (restrictive cardiomyopathy) had received radiotherapy, as had one of the other three patients with an EA ratio $\geqslant 3 \cdot 0$, who was apparently asymptomatic at the time of study. Thus, despite the smaller cavity size found in the patients who received irradiation any differences in diastolic function associated with irradiation in the small group of symptomatic patients did not achieve statistical significance. In patients with $\mathrm{SF}<30 \%$, IVRT was significantly shorter $(P=0.002)$ in the nine patients who had been irradiated than in the 42 who had 
not. Of patients who received anthracycline $>$ $300 \mathrm{mg} / \mathrm{m}^{2}$ with or without irradiation $(\mathrm{n}=$ 15 and 92 respectively), LV dimensions were reduced, IVRT shorter $(P=0.01)$ and the velocity integral ratio higher $(P=0.05)$ in the irradiated patients.

\section{EFFECTS OF TIME FROM TREATMENT}

Patients were stratified for examination by time from treatment:

$\leqslant 2$ years from first treatment $(n=25)$;

$>2-5$ years from first treatment $(n=81)$;

$>5-10$ years from first treatment $(n=82)$; and

$>10$ years from first treatment $(n=38)$.

There was no significant change in the frequency of irradiation with time from first treatment. No patient was symptomatic in this study population at $\leqslant 2$ years from first treatment but there was no significant relation between incidence of symptoms and time from treatment. The number of symptomatic patients, however, is rather small for this analysis.

\section{RELATION BETWEEN SF AND TIME FROM TREATMENT}

The incidence of $\mathrm{SF}<30 \%$ increases markedly with time from treatment (fig 4), only $4 \%$ of patients with SF $<30 \%$ were treated $\leqslant 2$ years ago, while $61 \%$ of them were first treated $>10$ years before $(\mathrm{P}<$ $0.0001, \chi^{2}$ test). SF is inversely proportional to time from first treatment for the whole study population $(r=-0.47 \quad(\mathrm{P}<0.0001)$ and the strength of this relation increases with dose. The relation between SF and cumulative dose is maintained irrespective of time from treatment. A true relation between time from treatment and SF therefore seems probable, which may be more important at higher anthracycline doses.

POSTERIOR WALL THICKNESS AND TIME FROM TREATMENT

Systolic posterior wall thickness was also inversely proportional (as a percentage of control) to time from first treatment $(r=-0.34, \mathrm{P}$ $<0.0001)$. The reduction in wall thickness with time from treatment was most striking at doses $>300 \mathrm{mg} / \mathrm{m}^{2} \quad(r=-0.49, \quad \mathrm{P}<0.0001$

Figure 4 Cluster plot showing the numbers of patients with left ventricular shortening fraction $(S F)<30 \%(n)$ within each anthracycline dose group (N) stratified by time from first anthracycline exposure. The proportion receiving higher doses does not seem to have altered over time $(P=0.5)$, and the proportion of patients with reduced SF increases with time from first treatment $(P<0.0001)\left(\chi^{2}\right.$ test $)$ for systolic wall thickness at $401-500 \mathrm{mg} / \mathrm{m}^{2}$ ). Although posterior wall thickness is not directly related to dose according to overall linear regression analysis, a relation between wall thinning and dose was apparent for those treated $>5$ years previously $(r=-0.3$, $P<0.01)$.

\section{DIASTOLIC FUNCTION AND TIME FROM} TREATMENT

The prevalence of abnormalities of diastolic function also increased with time from treatment. No patient had $\mathrm{E}<0.68$ at $\leqslant 2$ years but the incidence increased with time from first treatment and was $34 \%$ after $>10$ years $\left(P=0.005, \chi^{2}\right.$ test). There was also a tendency for the proportion of patients with peak A velocity $<0.36 \mathrm{~ms}^{-1}$ to increase. Thus there was no overall trend for change in EA ratio, but the incidence of abnormal EA ratio (either $<1.38$ or $>2.36$ ) increased with time from $44 \%$ at $\leqslant 2$ years to $58 \%$ at $>10$ years $(P=0.03)$. These abnormalities were present irrespective of dose.

GENDER

There were no differences in the incidence of symptoms or reduced SF according to patient's sex, either overall or in relation to anthracycline dose sensitivity. Similarly, there were no absolute differences in SF or any other LV functional parameter (separable from BSA) between males and females either overall or within any dose group.

\section{Discussion}

Significant abnormalities of left ventricular diastolic filling patterns are associated with prior anthracycline treatment. The incidence of symptomatic cardiac failure and abnormalities of left ventricular systolic function seen in this study is similar to those reported by other groups. ${ }^{15-17}$ The relations between the incidence and severity of myocardial dysfunction, cumulative anthracycline dose, and elapsed time from treatment are clearly seen. The increase in the dose related posterior wall thinning with elapsed time from treatment has not previously been demonstrated and lends support to the hypothesis that late myocardial decompensation in this condition is due to failure of myocardial growth ${ }^{16}$ and continuing myocyte loss. Thus it is not unreasonable to attribute the abnormalities of diastolic filling also found in these patients to anthracycline induced cardiotoxicity. Examination of the patterns of diastolic dysfunction associated with prior anthracycline treatment offers potentially important insights into the polyphasic nature of myocardial impairment by anthracycline agents.

Early diastolic filling appears to be normal or enhanced at low anthracycline doses or when systolic function is preserved, with earlier onset of rapid early filling (shorter IVRT) which terminates abruptly (faster deceleration for a shorter time). When heart rate is relatively normal there is also more time left for the atrial phase filling, so although the EA 
ratio is normal, the velocity integral ratio is reduced. There is a reduction in early filling at higher doses or in the presence of reduced SF, with a slower onset of early filling (longer IVRT and acceleration time) despite the increased heart rate, ${ }^{18}$ with a reduced $E$ velocity and shorter deceleration time. Thus atrial filling starts earlier, peak A velocity is increased and A velocity integral is also raised, so EA and velocity integral ratios are reduced. The incidence of abnormally low peak $E$ velocity and abnormal EA ratio also increases with time from treatment. Some patients exhibit a more classical "restrictive" pattern of diastolic filling, mainly but not exclusively in association with prior cardiac irradiation.

It has been proposed that abnormalities of Doppler echocardiographic patterns of LV filling change in accordance with the relative degrees of abnormalities of active myocardial relaxation and passive LV compliance.$^{8}$ It is therefore possible to postulate some correlations between the filling patterns seen in this study and the underlying anthracycline induced myocardial damage, which although not directly examined in these patients, is well documented in other series. ${ }^{1920}$ It might be suggested that in milder degrees of damage associated with sarcoplasmic vacuolation and myofibrillar loss in affected myocytes and compensatory hypertrophy of less affected ones normal SF is maintained by (or at least associated with) enhanced early diastolic filling. The earlier onset of filling might be attributed to a small increase in early diastolic atrioventricular pressure gradient; the mild relaxation abnormality in the presence of a normal heart rate means that filling continues later in diastole (reduced velocity integral ratio (velocity integral of $\mathrm{E}$ wave $(\mathrm{cm}) /$ velocity integral of entire transmitral flow complex $(\mathrm{cm})$ ), so that left ventricular filling is optimal before systole starts. There seems to be a more obvious abnormality of diastolic relaxation in those with worse myocyte loss, variable interstitial fibrosis, and more marked residual myocyte hypertrophy. Reduced SF in these patients is associated with prolonged isovolumic relaxation, sluggish, low velocity early filling, and an increased late diastolic contribution to LV filling with increased heart rate. In the most severely affected patients the relaxation abnormality may become so marked, fibrosis (and therefore reduced compliance) so predominant, or LV dilatation and mitral regurgitation so severe that $\mathrm{LV}$ end diastolic pressure and hence left atrial pressure increases further, IVRT shortens, peak A velocity decreases, and the EA ratio rises, even in the presence of low peak $E$ velocity.

\section{TECHNICAL CONSIDERATIONS}

While the pathophysiology of anthracycline cardiotoxicity provides an attractive explanation for the observed diastolic filling patterns there are some difficulties with overall interpretation of group data and technical limitations of the technique which merit discussion. The individual biological variation in tissue response to anthracycline treatment probably explains at least some of the wide confidence limits for group data. Even in controls, "1 however, the "normal range" for a given BSA is fairly wide (probably related to the broad range of normal heart rates in children) and it is therefore difficult to delineate clearly degrees of abnormality for individuals except at extremes.

Transmitral flow velocities measured by Doppler echocardiography are influenced by several technical factors. Potential for such variability was minimised in this study by using the carefully predefined study and analysis protocol documented previously, ${ }^{11}$ and all scans were performed and analysed by a single observer. Precise location of the sample volume was emphasised and respiratory variation was minimised by selection of multiple similar Doppler complexes with the highest peak $\mathrm{E}$ velocity and a clear $\mathrm{A}$ wave. ${ }^{11}$ Other sources of variability have been reported $^{2122}$ and in common with the authors' studies are largely between $5 \%$ and $10 \%$, with more error for flow time measurements than for absolute velocities.

\section{LOADING CONDITIONS}

Diastolic filling is also affected by haemodynamic loading conditions ${ }^{10} 2324$ and particularly by heart rate $^{1825}$ and it might be suggested that the filling abnormalities simply reflect increased heart rate due to arousal. The increase in heart rate, however, was not uniform across the dose range, and the rate was relatively normal in those treated at doses $<200 \mathrm{mg} / \mathrm{m} .^{2}$ Most patients are not aware of their own anthracycline dose and thus relative risk. Increased resting heart rate was clearly related to treatment intensity in this study and was most apparent at the highest doses and lowest SF. This increased heart rate would tend to increase the peak A velocity but would not be associated with the prolonged isovolumic relaxation and acceleration times. ${ }^{1825}$ Thus some of the apparent abnormalities of diastolic filling may relate to pathological increase in heart rate but there is still evidence for impaired relaxation and compliance. The chronotropic response to anthracycline induced myocardial injury is also of interest.

Preload is likely to be normal in these patients who were "well" and neither clinically anaemic nor subject to fluid load. Afterload is probably increased in the presence of reduced posterior wall thickness and more so at higher doses and increased length of time from treatment. Although patients were individually normotensive, overall systolic and diastolic blood pressures were higher than control values, particularly at the highest anthracycline doses. Similarly, LV diameter increased in a dose related manner. Thus afterload is highest in the more severely affected patients. Studies with pharmacological increase of afterload show delays in the onset of LV filling but no consistent effect on relative contributions of early and atrial phases of LV filling. ${ }^{26}$ Thus while loading conditions may have some bearing on the observed diastolic filling abnormalities, 
anthracycline treatment clearly has significant effects on $\mathrm{LV}$ diastolic function in children. Abnormalities of active relaxation capacity or passive compliance, or both, may occur, according to the relative importance of myocyte loss, residual myocyte hypertrophy, and interstitial fibrosis in each individual.

\section{CLINICAL RELEVANCE}

The additional detrimental effects of cardiac irradiation and length of time from treatment are readily understood from the underlying pathophysiology of anthracycline cardiotoxicity. Cardiac irradiation produces interstitial fibrosis, ${ }^{192028}$ as well as coronary artery injury and pericarditis. ${ }^{29-31}$ One patient manifested the full range of combined anthracycline and radiation induced cardiac damage, with recurrent pericarditis, a friction rub, and gallop rhythm being detectable clinically. Figure 5 shows the echocardiographic features of this patient, with markedly increased pericardial and endocardial echogenicity, myocardial thinning, mild LV dilatation, and reduced SF. Diastolic filling was markedly abnormal with an EA ratio of $>4: 1$. Patients who received

Figure 5

Echocardiographic features of anthracycline cardiomyopathy complicated by radiation induced myocardial and pericardial damage. The cross sectional

echocardiogram (diastolic frame, parasternal long axis view) showis mild left ventricular dilation (body surface area $=1 \cdot 3 \mathrm{~m}^{2}$ ) with myocardial thinning and greatly increased pericardial and

endocardial echogenicity.

These features are also well demonstrated on the $M$ mode echocardiogram along with the reduced shortening fraction. Diastolic filling is markedly abnormal with short isovolumic relaxation time and deceleration time from peak $E$ velocity and markedly elevated $E A$ ratio of $4 \cdot 3: 1$; the atrial phase filling peak is barely visible above the baseline. $A$, peak atrial phase filling velocity; $E$, peak early filling velocity; ECG, electrocardiogram; $L A$, left atrium; $L V$, left ventricular cavity; Phono', phonocardiogram; $R V$, right ventricular cavity; S1, S2, and S3, first to third heart sounds.
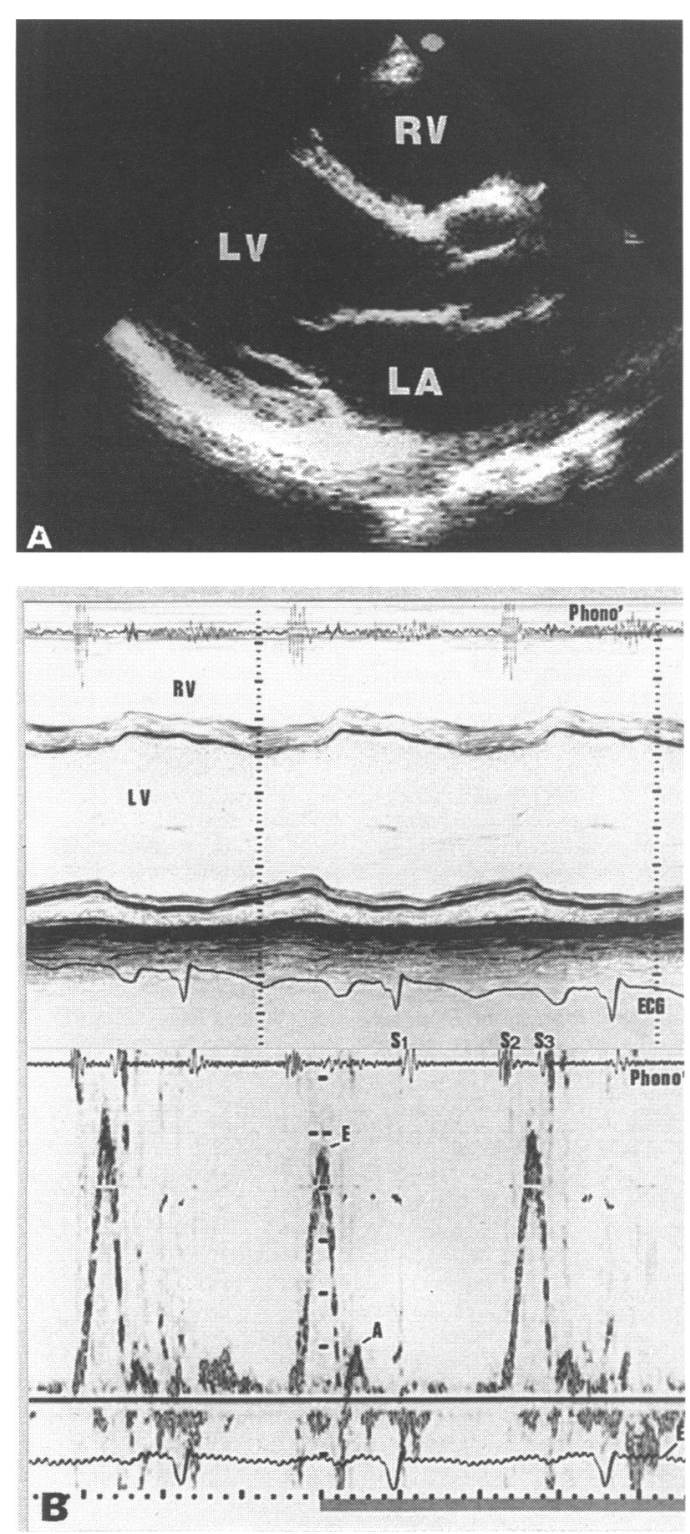

radiotherapy do not appear to have so much LV dilatation and changes in SF may be less marked despite a higher incidence of symptoms (although those with worse SF may have already been "selected out" previously). They also have a tendency to the more classical restrictive pattern of diastolic filling, ${ }^{32}$ a smaller, non-compliant LV generates higher left atrial pressures, leading to a shorter IVRT, rapid but abbreviated early filling, and a reduced atrial contribution to diastolic filling. The degree of myocardial fibrosis is variable even in non-irradiated patients ${ }^{20}$ and Doppler echocardiography may provide a useful indicator of those particularly at risk from impaired LV compliance ${ }^{33}$ whether or not $S F$ is reduced.

The net effect of LV wall thinning from myocyte loss, LV dilatation, and increased blood pressure is likely to be an increase in LV afterload. This is likely to impose continuing stresses on the remaining myocytes, which may also have to grow excessively as a child becomes an adult. Continuing myocyte loss is therefore likely over time, resulting in a vicious cycle which can eventually lead only to failure of compensatory mechanisms and overt cardiac decompensation. While pharmacological reduction of afterload ${ }^{34}$ will not restore histological normality, reduction of blood pressure and LV wall distending force may reduce the effects of abnormalities of relaxation and compliance. It might also reduce the rate of further myocyte drop out, and thus might theoretically have a beneficial effect on preservation of residual myocardial function as well as on symptomatology. Careful monitoring, however, of the effects of such intervention on cardiac function is required. Patients with particularly fibrotic ventricles ${ }^{35-37}$ and restrictive type diastolic filling patterns can have major problems from vasodilator treatment without adequate preload (preload may be reduced by diuretic treatment); knowledge of diastolic filling patterns in such patients might be particularly helpful.

\section{Conclusions}

There is marked individual variation in the degree of myocardial damage produced by anthracyclines, both histologically and clinically. Different patterns of abnormal LV diastolic filling are seen at different stages of anthracycline induced myocardial damage in children and, like systolic function, probably worsen with time from treatment. It appears that transmitral Doppler diastolic flow patterns within the known limits of the technique may provide a non-invasive "handle" on the underlying myocardial pathophysiology in children previously treated with anthracyclines. It is possible that such pathophysiology also has an influence on clinical outcome, although further studies of larger numbers of patients with systolic dysfunction would be required to confirm this suggestion. Doppler echocardiography appears particularly sensitive for the "restrictive" type of myocardial 
damage associated with combined anthracycline treatment and cardiac irradiation, and, in some patients, after treatment only with anthracyclines. Identification of patients with abnormal LV compliance may be particularly helpful and may have therapeutic implications.

Doppler echocardiographic assessment of diastolic LV function is a non-invasive technique which is readily applicable to large numbers of small children. It can provide information on myocardial pathophysiology unavailable from $M$ mode assessment of $\mathrm{LV}$ systolic function and may have significant management and therapeutic implications. Its part in prospective assessment of progressive ventricular dysfunction requires further clarification.

The authors thank Maggie Shapland (Bristol University Computing Service) for database construction and support, Dr Rosemary Greenwood (Institute of Child Health, Bristol) for statistical advice and consultant paediatricians and their staff from the southwest region for their help with clinical data and patient retrieval. FAB was supported by the Cancer Research Campaign and MGM is supported by the Cancer and Leukaemia in Childhood Trust.

1 Grossman W. Diastolic dysfunction and congestive heart failure. Circulation 1990;81(suppl III):1-7.

2 Cohn JN, Johnson G. Heart failure with normal ejection fraction: the V-HeFT study. Circulation 1990;81(suppl III):48-53.

3 Packer M. Abnormalities of diastolic function as a potential cause of exercise intolerance in chronic heart failure. Circulation 1990;(suppl III):78-86.

4 Bleyer WA. The impact of childhood cancer on the United States and the world. $C A 1990 ; 40: 355-67$.

5 Lee BH, Goodenday LS, Muswick GJ, et al. Alterations in left ventricular diastolic function with doxorubicin
in in left ventricular diastolic function with

6 Hausdorf G, Morf G, Beron G, et al. Long term doxorubicin cardiotoxicity in childhood: non-invasive evaluation of the contractile state and diastolic filling. $\mathrm{Br}$ Heart $f$ 1988;60:309-15.

7 Labovitz AJ, Pearson AC. Evaluation of left ventricular diastolic function; clinical relevance and recent Doppler echocardiographic insights. Am Heart $f$ 1987;114(1): 836-51.

8 Appleton CP, Hatle LK, Popp RL. Relation of transmitral flow velocity patterns to left ventricular diastolic function: new insights from a combined hemodynamic and Doppler echocardiographic study. $\mathcal{F} \mathrm{Am}$ Coll Cardiol 1988;12:426-40.

9 Nishamura RA, Housmans PR Assessment of diastolic function of the heart: background and current applicafunction of the heart: background and current applications of Doppler echocardiography: Part I. Physiologic and pathoph

10 Nishamura RA, Abel MD, Hatle LK, Tajik J. Assessment of diastolic function of the heart: background and current applications of Doppler echocardiography: Part II. Clinical studies. Mayo Clin Proc 1989;64:181-204.

11 Bu'Lock FA, Mott MG, Martin RP. Left ventricular diastolic function in children measured by Doppler echocardiography: normal values and relation with growth. $B r$ Heart $\mathcal{f} 1995$; in press.

12 Marchandise B, Schroeder E, Bosly A, et al. Early detection of doxorubicin cardiotoxicity; interest of Doppler echordicophic analysis of left ventricular filling dynamics. Am Heart 7 1989;118(1):92-8.
13 Bu'Lock FA, Mott MG, Martin RP. Doppler echocardiographic detection of anthracycline induced changes in diastolic ventricular function in children [abstr]. $B$ Heart f 1990;64:85P

14 The Criteria Committee of the New York Heart Association. Diseases of the heart and blood vessels; nomenclature and criteria for diagnosis. 6th ed. Boston: Little, Brown, 1964.

15 Von Hoff DD, Layard MW, Basa P, et al. Risk factors for doxorubicin-induced congestive heart failure. Ann Intern Med 1979;91:701-17.

16 Lipshultz SE, Colan SD, Gelber RD, et al. Late cardiac effects of adriamycin therapy for childhood acute lymphoblastic leukaemia. $N$ Engl f Med 1991;324:808-15.

17 Steinherz L, Steinherz P, Tan CTC, Heller G, Murphy ML. Cardiac toxicity 4-20 years after completing anthracycline therapy. $\Im A M A 1991 ; 266: 1672-7$.

18 Stewart RAH, Joshi J, Alexander N, Nihoyannopoulous $P$ Oakley CM. Adjustment for the influence of age and heart rate on Doppler measurements of left ventricular heart rate on Doppler measureme

19 Billingham ME, Mason JW, Bristow MR, Daniels JR. Anthracycline cardiotoxicity monitored by morphologic changes. Cancer Treat Rep 1978;62:865-72.

20 Billingham ME, Bristow MR, Glatstein E, et al. Adriamycin cardiotoxicity, endomyocardial biopsy evidence of enhancement by irradiation. Am $\mathcal{f}$ Surg Pathol 1977;1:17-23.

21 Fast J, van Dam I, Heringa A, De Boo T, et al. Limits of reproducibility of mitral pulsed Doppler spectra. $A m \mathcal{F}$ Cardiol 1988;61:891-4.

22 Spirito P, Maron BJ, Verter J, Merrill JS. Reproducibility of Doppler echocardiographic measurements of left venof Doppler echocardiographic measurements of left ven-

23 Thomas JD, Weyman AE. Echocardiographic Doppler evaluation of left ventricular diastolic function: physics evaluation of left ventricular diastolic function:
and physiology. Circulation 1991;84(3):977-90

24 Stoddard MF, Pearson AC, Kern MJ, et al. Influence of alteration in preload on the pattern of left ventricular diastolic filling as assessed by Doppler echocardiography in humans. Circulation 1989;79:1226-36.

25 Oniki T, Hashimoto Y, Shimizu S, et al. Effect of increasing heart rate on Doppler indices of left ventricular performance in healthy men. Br Heart $\mathcal{f} 1992 ; 68: 425-9$.

26 Colan SD, Borow KM, Neumann A. Effects of loading conditions and contractile state (methoxamine and dobutamine) on left ventricular early diastolic function in normal subjects. Am $\mathcal{F}$ Cardiol 1985;55:790-6.

27 Smith SA, Stoner JE, Russel AE, Sheppard JM, Aylward PE. Transmitral velocities measured by pulsed Doppler in healthy volunteers: effect of acute changes in blood pressure and heart rate. Br Heart $\mathcal{f} 1989 ; 61: 344-7$.

28 Isner JM, Ferrans VJ, Cohen SR, et al. Clinical and morphological findings after anthracycline chemotherapy. phological findings after anthrac

29 Hancock SL, Donaldson SS, Hoppe RT. Cardiac disease following treatment of Hodgkin's disease in children and adolescents. $₹$ Clin Oncol 1993;11:1208-15.

30 Fajardo LF, Eltringham JR, Stewart JR. Combined cardiotoxicity of adriamycin and $\mathrm{X}$-radiation. Lab Invest 1976;34:86-96.

31 Gottdeiner JS, Katin MJ, Borer JS, Bacharach SL, Green MV. Late cardiac effects of therapeutic mediastinal irradiation. $N$ Engl $₹$ Med 1983;308:569-70.

32 Appleton CP, Hatle LK, Popp RL. Demonstration of restrictive ventricular physiology by pulsed Doppler
echocardiography. $f$ Am Coll Cardiol 1988;11(4): 757-68.

33 Mortensen SA, Olsen HS, Baandrup U. Chronic anthracycline cardiotoxicity: haemodynamic and histological manifestations suggesting a restrictive endomyocardial manifestations suggesting a restrict

34 Lipshultz SE, Colan SD, Mone SM, et al. Afterload reduction therapy in long term survivors of childhood cancer tion therapy in long term survivors of childhood can

35 Mortensen SA, Olsen HS, Baandrup U. Chronic anthracycline cardiotoxicity: haemodynamic and histological cline cardiotoxicity: haemodynamic and histological manifestations suggesting a restrict

36 Conroy B, Guthrie W. Endocardial fibroelastosis associated with fatal Adriamycin (doxorubicin) cardiomyopathy during treatment of Ewing's sarcoma. Scot Med ₹ 1983;28:295-9.

37 Wilcox RG, James PD, Toghill PJ. Endomyocardial fibrosis associated with daunorubicin therapy. Br Heart f 1976, 38:860-3. 